\title{
Whole Language and Phonics: Which Instructional Practices a Most Effective in Teaching At-Risk Students to Read?
}

\author{
Tamara Senior, Alison Arrow, Keith Greaney
}

\begin{abstract}
A disproportionate number of New Zealand students fail to learn to read. Children from low socioeconomic backgrounds are over-represented among New Zealand's under-achieving readers. This study investigated the extent to which teachers of beginning readers in low-decile schools emphasised explicit phonological-based instruction, as well as the relationship between teacher emphasis on phonological instruction and student progress in reading-related skills. Results demonstrated that children from different literacy instruction programmes progressed similarly in all reading-related skills except word reading. Students receiving explicit phonologicalbased literacy instruction made superior progress in word reading skills over children receiving implicit phonological-based instruction. A strong emphasis on explicit phonological instruction was also associated with a reduction in variation of class word reading scores over time. The study findings support previous research demonstrating that phonological awareness and decoding skills play a crucial role in the development of word reading ability and that explicit phonological-based instruction can attenuate differences in word reading development. Implications for teachers and policy makers are described.
\end{abstract}

Keywords: literacy, phonological instruction, reading

\section{Research Paper}

\section{INTRODUCTION}

\section{Theories of Reading: Searchlights and the Simple View of Reading}

The two most widely-used models of reading development are the Searchlights or 'multiple cues' theory and the Simple View of Reading (SVR). The multiple cues model claims that readers use information from four sources in order to read: meaning, sentence structure, visual cues, and phonological cues (Clay \& Cazden, 1990). According to multiple cues theory, readers should focus primarily on meaning while 'cross-checking' the multiple sources of information against each other. Only when this "higher-order" strategy falters should the reader look more closely at individual sources of information such as letter-sound cues (Clay \& Cazden, 1990). The multiple cues approach tends to emphasise the development of unconstrained skills such as vocabulary and comprehension in order to support reading (Tunmer, Chapman, Greaney, Prochnow \& Arrow, 2013).

In contrast to the multiple cues theory, the SVR emphasises the importance of underlying constrained skills such as phonological and decoding ability (skill in converting letters and letter strings into phonological representations) (Allan \& Harwood, 2014) alongside comprehension skills (Stuart, Stainthorp \& Snowling, 2008; Tunmer et al., 2013). The SVR states that reading is a product of decoding and listening comprehension (Gough \& Tunmer, 1986). According to the SVR, reading cannot be achieved without adequate decoding and listening comprehension; having just one or the other is not sufficient to access text independently (Gough \& Tunmer, 1986).

\section{Reading Development}

Key instructional components necessary for the development of reading have been welldocumented. In their 2001 report on current reading research instruction, the National Reading Panel identified five 'pillars' required for comprehensive reading instruction: phonological awareness, instruction in graphophonemic relationships, vocabulary knowledge, fluency, and comprehension (Anderson, 2009).

\section{Phonological Awareness}

Prior to learning to decode text, a child needs to acquire sensitivity to the sounds of spoken language (McNamara, Scissons \& Gutknecth, 2011). Phonological awareness is the ability to consciously identify and manipulate sounds in speech (Stanovich, 1986), and phonemic awareness is the ability to 
identify and manipulate the smallest sounds within speech (National Reading Panel, 2000). Because spoken language is oriented around meaning, children do not usually become aware of the individual sound units that make up words without some form of explicit instruction (Lundberg, Larsman \& Strid, 2012). Thus, instruction plays a key role in developing specific phonological abilities for most children (Shankweiler \& Fowler, 2004). Moreover, it is essential that children grasp the relationships between sounds and letters early in their reading development. If not, they may be forced to use other, unhelpful cues such as syntax or semantics in their reading (Tunmer \& Prochnow, 2009).

\section{Graphophonemic Decoding and Orthographic Knowledge}

Once phoneme awareness has begun to develop, children can begin to understand the way sounds and letters are linked by learning which individual sounds are visually represented by which letters (Shankweiler \& Fowler, 2004). Most children need explicit teaching in letter-sound correspondences, with knowledge of initial letter-sound correspondences being consolidated and extended through the introduction of basic words that use the same letter-sound patterns (Rayner, Foorman, Perfetti, Pesetsky \& Seidenberg, 2001).

Understanding of letter-sound correspondences enables children to begin unlocking the alphabetic code - a vital step towards independence in learning to read (Stanovich, 1986). The idea that progress in reading can become self-perpetuating is known as the self-teaching hypothesis (Allan \& Harwood, 2014). The self-teaching hypothesis is supported by research which demonstrates that children, once in possession of enough knowledge about graphophonemic correspondences, can independently go on to deduce further graphophonic knowledge through successful experiences in sounding out new words (Conners, Loveall, Moore, Hume \& Maddox, 2011).

When a child first begins to use their knowledge of letter-sound correspondence to decode words, their attempts are conscious and sometimes laborious (Ehri, 2005). Through practice in accurately decoding frequently-encountered letter strings and making successful attempts to pronounce new words using decoding ability, graphophonic knowledge becomes cemented in orthographic memory and is thereby available for future encounters with unknown words containing familiar letter strings (Arrow \& Tunmer, 2012). The connections formed between phonemes and graphemes become triggers to enable rapid retrieval of word pronunciations as well as meanings (Ehri, 2005). Having access to a mental store of partial word representations enables children to read with less reliance on laborious phoneme-grapheme decoding; they are able to recode larger units of print rapidly into phonological representations that match words stored in their vocabulary (Arrow \& Tunmer, 2012).

An ability to use the alphabetic code is crucial in developing automaticity in word reading (Simos et al., 2007). Phonological decoding is more useful than a reliance on orthographic decoding when learning new words because learning new words via phonological recoding is likely to result in fewer identification errors and more rapid orthographic recognition than learning words via visual representation only (Kyte \& Johnson, 2006). Indeed, it is the very process of phonological decoding that causes the orthographic representation of words to become entrenched in memory (Juel \& Minden-Cupp, 2000; Kyte \& Johnson, 2006; Simos et al., 2007).

\section{Children at Risk of Reading Failure}

Research indicates that children from low socioeconomic backgrounds are more at risk of reading failure than children from high socio-economic backgrounds (D'Angiulli, Siegel \& Hertzman, 2004; Kieffer, 2010). There is evidence indicating that children from low-income backgrounds in New Zealand face a disproportionately high risk of reading failure (Greaney, 2004; Tunmer et al., 2013).

\section{Impact of Schooling}

The methods needed to teach a new-entrant child to read depend on what skills the child brings to school ( HM Treasury Department for Education and Skills, 2007). However, the first priority for at-risk beginning readers is the development of phonological awareness and understanding of the alphabetic principle (Rayner et al., 2001; Tunmer et al., 2008). Research demonstrates that children lacking readingrelated skills such as phonological awareness and knowledge of the alphabetic code at school entry, benefit most from instruction that is explicit, systematic, intensive, and rich in opportunities to practise skills that have been learned in isolation from connected text (Jimerson, Oakland \& Farrell, 2006). Research also indicates that while children from low socio-economic backgrounds tend to be at higher risk of reading failure (Noble, Farah \& McCandliss, 2006), schooling can attenuate these risks substantially.

\section{Explicit and Systematic Instruction}

Children who come to school with limited readingrelated skills need explicit instruction in phonological awareness and graphophonic relationships, including letter-sound matching (Connor, Morrison \& Katch, 
2004; National Reading Panel, 2000). Teachers cannot assume that children are able to hear individual sounds in words or make connections between sounds and print (Torgesen, 2004). As Torgesen (2004) explains, explicit instruction involves the teacher deliberately focusing the child's attention on letter-sound connections.

Teaching, for children at risk of reading failure, also needs to be systematic - that is, to follow a planned structure geared to address the needs of the students. Following a review of reading research, Ehri (2004) reflected that any phonological-based programme (either in prevention or remediation of reading difficulties) is more effective if it is systematic. However, in order to plan a systematic phonologicalbased programme to address the specific needs of students, assessment of phonological awareness needs to be comprehensive (Anthony \& Francis, 2005). Teacher knowledge about the exact phonological needs of students allows for the planning of instruction to cater for specific skill gaps which could, if ignored, lead to reading failure in the future (Anthony \& Francis, 2005).

\section{Intensity of Instruction}

Explicit, systematic instruction that provides opportunities for skills practice in isolation and in connected text will be of limited benefit unless it is provided with sufficient intensity. Research on reading programmes for prevention and intervention supports the idea that increasing the intensity of phonics programmes by reducing group size and tailoring instruction time is most beneficial for children at risk for (or experiencing) reading failure (Hansen, Litzelman, Marsh \& Milspaw, 2004).

\section{Skills in Isolation and Practice in Context}

Beginning readers benefit from skills instruction that takes place in isolation from connected text, followed by opportunities to practise their skills within connected text (Tunmer \& Chapman, 2003). Researchers suggest that the usefulness of first teaching skills in isolation can be attributed to four factors: children are able to focus their attention on letter-sound patterns; employment of letter-sound skills is useful for all texts, whereas the helpfulness of context cues depends on the specific text being read; being forced to rely on letter-sound cues when skills are taught in isolation discourages the reader from relying on context cues; and isolated instruction in letter-sound skills encourages the struggling reader to see that these skills are actually more reliable than context cues (Ryder, Tunmer \& Greaney, 2008).
Researchers caution that the teaching of new words in connected text may only be useful to children once they have learned at least some decoding skills. For younger children who have not yet developed the ability to use graphophonic correspondence, solely learning new words in the context of text could be detrimental because they are likely to begin to rely on cues that exclude the use of graphophonic relationships (Harwood, 2006). Where the use of graphophonic relationships is limited, children are more likely to make incorrect orthographic-phonological correspondence (Share, 1999). Children who have adequate decoding skills, however, are able to use context to aid them in developing their orthographic knowledge further (Allan \& Harwood, 2014).

The recommendation to teach decoding strategies in isolation does not imply that beginning readers should not be reading connected text. On the contrary, children at risk of reading failure need mileage in reading connected text if they are to learn how to apply their skills in practice (Tunmer et al., 2007). However, research demonstrates that graphophonic cues are more useful for beginning readers than contextual cues, and therefore children need to be supported to use the letter-sound cues primarily when reading connected text (Rayner et al. 2001; Tunmer \& Chapman, 2003).

\section{READING INSTRUCTION IN NEW ZEALAND}

\section{Whole Language Heritage}

In the past, New Zealand held a predominantly whole-language theory of reading instruction. The whole language approach to literacy instruction marked a departure from explicit teaching of the rules and regularities involved in decoding of text to a study of language-meaning within the context of texts (Smith \& Goodman, 1971). A wholelanguage reading programme is non-prescriptive because whole-language theory emphasises using child-motivation and experience as a basis from which to teach reading - often within the context of a relevant and interesting theme (Tracey \& Morrow, 2006). Historically, the whole-language view of reading development promoted the idea that reading, like language, is a naturally-acquired skill that develops when children are surrounded by captivating literature (Rayner et al., 2001; Smith \& Goodman, 1971; Tracey \& Morrow, 2006). More recently, whole-language enthusiasts have begun to acknowledge that instruction in phonological skills should occur, but within the context of meaningful texts (Pressley, 2006). 
Certain aspects of the whole-language approach are not necessarily incompatible with a phonologicalbased approach, and are certainly beneficial for developing readers when employed alongside phonological-based methods to produce a balanced instructional programme (Rayner et al., 2001; Xue \& Meisels, 2004). However, the issue with a predominantly whole-language approach is the emphasis placed on meaning and context, which occurs at the expense of thorough and isolated instruction in essential phonological skills (Tunmer \& Chapman, 2003).

\section{Assessment of New Entrant Children}

An area of concern noted in an Education Review Office evaluation Reading and Writing in Years 1 and 2 (Education Review Office, 2009) is the lack of attention paid to the progress of children in their first year at school. Research demonstrates that there are very few, if any, remediation programmes that can remediate most children successfully (Torgesen et al., 2001). It follows that in order for most children to succeed in reading, they need to progress adequately from the moment they begin school. Research also indicates that phonological awareness is a significant predictor of reading development (National Early Literacy Panel, 2008). In order to avoid the 'wait to fail' approach where children are not identified for support such as Reading Recovery until the formal Observation Survey conducted after one year at school (Greaney \& Arrow, 2012), teachers need to know exactly what level of phonological awareness and other reading-related skills each of their students possess as soon as they begin school. Apart from letter-sound knowledge and hearing and recording sounds, the Observation Survey tool (Clay, 2005) provides little specific information on phonological awareness. A poor result may indicate that a child is at risk for reading difficulties. However, unless an assessment produces detailed information about the specific phonological skills a child is lacking, an educator will have limited knowledge about how to prevent reading failure (Anthony et al., 2003).

\section{Multiple Cues Theory and Ready-to-Read Texts}

Despite the importance of phonological-based instruction for beginning readers, a constructivist view of reading development is encouraged in many New Zealand classes (Greaney, 2011; Tracey \& Morrow, 2006), where beginning readers are encouraged to use syntactic and semantic cues as well as graphophonic cues in order to predict unfamiliar words (Ministry of Education, 2003). An over-emphasis of context-based teaching recommendations (which comes at the expense of phonological-based recommendations) is particularly unhelpful for at-risk beginning readers, as these children need explicit instruction in word-level skills and strategies in order to make the connections necessary to become independent readers (Tunmer et al., 2013).

The Ministry of Education has also shown a preference for the multiple cues theory in the text series recommended for use with beginning readers (Eber, 2001). In their curriculum support tool entitled Literacy Learning Progressions: Meeting the Reading and Writing Demands of the Curriculum (2010), the Ministry of Education states that the Ready-toRead book series should be the main resource used by teachers of beginning readers. The Ministry of Education also supplies these books free-of-charge to all state and integrated schools in New Zealand (Van Acker, 2007). While the Ready-to-Read series is levelled, sentences are simply constructed and vocabulary is supposedly familiar, the texts are chosen because they provide opportunity for students to "draw on their oral language", "make meaning", and "think critically" (Eber, 2001, p. 9). These texts have repetitive vocabulary and sentence structure, which make reading predictable rather than necessarily decodable. Beginning readers are provided with opportunities to practice repeated words but limited opportunities to practice repeated graphophonic patterns in different words (Juel \& Minden-Cupp, 2000).

Research also indicates that Ready to Read books contain significantly less words than the other popular instructional series in New Zealand, the Price Milburn (PM) series (Van Acker, 2007). As Greaney states, there is a danger that struggling readers in classrooms which rely heavily on Ready-to-Read books may not be getting the mileage required to attain reading fluency (Van Acker, 2007). While many classrooms in New Zealand are likely to use a range of instructional reading materials, an over-reliance on the Ready-toRead series is not likely to be helpful for struggling readers (Van Acker, 2007).

\section{AIMS OF THE STUDY}

The following research questions were investigated in the current study:

1. To what extent is there evidence of phonologicalbased literacy teaching and assessment practices in new-entrant classes of low-decile schools?

2. What is the relationship between methods of literacy instruction and literacy progress in the first year of school? 


\section{METHOD}

An embedded mixed-method approach (Creswell, 2008) was used to examine relationships between instructional methods and aspects of literacy progress in new entrant children during their first year of school. Quantitative data was gathered via repeated measures of student skills as well as single systematic observational recordings of teacher methods. The qualitative data were gathered concurrent with the quantitative data through narrative recordings of teacher observations and individual teacher interviews.

Naturally-occurring independent class groups were allocated to either an 'explicit phonics' group or an 'implicit phonics' group based on the emphasis their teachers placed on explicit phonics instruction. A measure of control was gained for the existence of non-equivalent groups by tracking group progress between two assessment times. The student data was gathered via reading-related assessments once at the beginning of the study (Time 1) and once towards the end of the study (Time 2).

\section{Participants and Setting}

Nine new-entrant teachers and the children from their classrooms took part in the study. These participants were drawn from four schools located in lower socio-economic areas of a small urban city in New Zealand. Three of these schools were Decile 2 and one school was Decile 3.

Forty-three children took part in the study, with ages ranging from 5.0 - 5.8 years. The majority ( $n$ $=37$ ) of children in the sample were from families who identified themselves as Maori. Each child was individually assessed on five measures designed to assess letter and sound knowledge, phonological awareness, and vocabulary skills. Testing took place on two occasions, the first towards the end of Term Two (June/July) and the second at the end of Term Three (August/September).

An observation of at least one literacy lesson in each participating classroom was conducted. Most lessons included guided reading sessions and guided, shared, or independent writing. A time sampling recording system was used in which the teacher's behaviour and the context in which it occurred (connected text or isolation) was recorded at 30-second intervals.

As occurred in Connor et al.'s (2004) study, teacher methods were categorised as Explicit/In context, Explicit/Out of context, Implicit/In context, or Implicit/ Out of context. The term explicit was used to describe direct teaching or practice of phonological awareness and/or alphabetic code. Examples included teacher prompts to use letter-/cluster-sound correspondence (e.g. "sound it out" or "what sound do those letters make?"). The term implicit was used to describe vocabulary instruction or practice, teacher reading out loud, child reading out loud or silently, listening to others read out loud (e.g. buddy reading, roundrobin reading), teacher prompts directing attention to meaning or syntax, instruction about meaning or syntax, dictation (e.g. teacher-child or child-teacher), discussions about texts, conventions of print, listening comprehension, or isolated word reading.

The context in which reading skills were being taught was also included within the coding method. Therefore, Explicit/In context indicated direct instruction within the context of connected text (book or piece of writing), while Explicit/Out of context described direct instruction or practice in the alphabetic code in isolation from connected text. Finally, a written narrative recording was made of each lesson in order to capture finer details such as examples of prompts used, sequences of events, and descriptions of activities.

Immediately prior to conducting the Time 2 child assessments, individual interviews were undertaken with each participating teacher. The interviews were designed to supplement classroom observations by providing information about each teacher's practice such as planning, assessment, methods for catering for struggling readers, and views on instructional methods and materials.

\section{RESULTS}

\section{Instructional Emphasis}

The explicit phonological emphasis scores (context and isolation combined) across teachers suggested two naturally-occurring groups divided by differences in mean percentages of time spent teaching explicit phonological strategies. The three Explicit Phonics teachers spent more time teaching explicit phonological strategies in isolation (e.g. identification of initial phonemes in spoken words) and in connected text (e.g. directing students to attend to letter-sound correspondences during reading). In contrast, the six Implicit Phonics teachers spent proportionately more time using implicit phonological-based methods such as emphasising reading and writing goals focused on meaning or concepts about print. Teachers in both groups were observed using explicit and implicit phonologicalbased strategies, but groupings were based on the proportion of time spent using these methods.

Overall, the teacher observations and interviews demonstrated that there was minimal evidence of explicit phonological-based teaching. Six out of 
nine teachers spent less than thirty percent of their literacy lessons explicitly emphasising phonologicalbased strategies. Observation findings indicated that the teachers in the Implicit Phonics group spent significantly less time on average emphasising explicit phonological-based teaching strategies than the three teachers in the Explicit Phonics group. Interview findings supported the observation findings to some extent, but there were discrepancies between the way some teachers described their literacy focus and the emphasis they were observed making in teaching practice. Implicit Phonics teachers were more likely to describe their literacy programmes as a mixture of whole-language and phonics, but all of these teachers demonstrated minimal evidence of explicit phonological emphasis. The interviews also indicated that the Implicit Phonics group of teachers were lesslikely to consider phonological skills development in their planning, use of prompts in guided reading, or in student assessment.

\section{Student Progress in Reading-Related Measures}

In order to examine the relationship between teacher emphasis on phonological teaching methods and student progress, students were assessed in readingrelated measures at Time 1 and Time 2. Student groups corresponded to their teacher groups, i.e. students whose teachers were in the Explicit Phonics group were also placed in the Explicit Phonics group, and students whose teachers were in the Implicit Phonics group were also in the Implicit Phonics group.

Statistical analyses revealed that both the Implicit Phonics group of students and the Explicit Phonics group made significant progress in letter-name and letter-sound knowledge, letter writing ability, and rime identification, but neither of the groups made significant progress in initial or final sound identification skills. The differences between group scores and between the two groups' rate of progress were not significant for any of the measures except word reading. Although Burt word reading scores did not differ significantly between the two groups overall, the Explicit Phonics group showed significantly greater progress in word reading scores over time.

Research shows that an emphasis on explicit phonological-based instruction can significantly increase the achievement of at-risk readers (Greaney \& Arrow, 2012). Before forming the two large groups of teachers (Explicit and Implicit Phonics), it was clear that there were two outlier teachers at either end of the Explicit-Implicit Phonics spectrum. Analysis of score variance within the classroom receiving the most-explicit instruction (Class A) and the least- explicit instruction (Class I) revealed that the variance in word reading scores was wide at Time 1 for both classes. However, the variance in scores decreased over time in Class A (Explicit Phonics) but increased over time in Class I (Implicit Phonics). Thus, as the Class A mean scores increased over time, the range in scores decreased. However, as the Class I mean scores increased over time, so did their range in scores; the gap between the lowest and highest readers was widening.

Observations during administration of the Burt measure indicated that just over half the children from each group made at least some attempt to decode at least one unknown word, or made errors that showed they were attending to at least the initial letter of words. However, none of the children from the Implicit Phonics group were successful in any of their attempts to decode unknown words. In contrast, four of the 14 students from the Explicit Phonics group were successful in at least some of their decoding attempts. These children made more frequent and more extended efforts to decode whole words (rather than just initial letters). Several children showed they were able to decode whole words but not yet able to blend the sounds together every time. All of the children who were successfully able to decode some words came from the class whose teacher demonstrated the most emphasis on explicit phonological instruction (Class A). Two of these children showed a particularly dramatic improvement from Time 1, when they knew one and two words respectively, to Time 2 when they scored 18 and 21 respectively.

\section{DISCUSSION}

The current study's observation and interview findings indicated that the majority of teachers placed little emphasis on explicit phonological instruction and high emphasis on implicit phonological-based instruction and use of multiple cues in reading. Given the large static gap between low- and high-achieving readers in New Zealand, and latest Progress in International Reading Literacy Study (PIRLS) results demonstrating that children from low socio-economic backgrounds make up the majority of the country's lowest-achieving readers (Chamberlain, 2013), the current study's findings regarding teacher instruction of at-risk beginning readers are concerning. It appears that teachers of children likely to be at risk of reading failure continue to practise implicit phonological-based reading instruction regardless of student learning needs at school entry. Given research showing that explicit phonological-based instruction can attenuate the gap between poor and good readers, it is imperative that teachers of at-risk 
beginning readers recognise the need to give students explicit and isolated instruction in phonological skills.

Current assessment practices of beginning readers are also of concern. Research demonstrates that phonological awareness is a direct contributor to reading progress (Anthony \& Francis, 2005), yet the current study indicated that most teachers neglected to assess children's phonological awareness at school entry. Comprehensive assessment is essential in informing instructional practice (Greaney \& Arrow, 2012). In order to tailor reading instruction to students' individual learning needs, teachers need to know what phonological skills their students possess as soon as they begin school. Given research demonstrating that remediation programmes are rarely successful (Torgesen et al., 2001) but that early identification of potential difficulties and immediate explicit phonological instruction can prevent reading failure (D'Angiulli et al., 2004), waiting until a child demonstrates significant reading delay before attempting intervention is both unnecessary and unethical. It is essential that teachers are not only made aware of the importance of comprehensive phonological skills assessment at school-entry but also provided with the direction necessary to carry out such assessment.

\section{CONCLUSION}

The current study's findings showed faster rates of progress in word reading scores and superior skill in word decoding in classes receiving the highest emphasis on explicit phonological instruction. These results are similar to previous findings suggesting that explicit phonological instruction is more helpful in teaching at-risk students to read than implicit phonological instruction. Moreover, the finding that a relatively strong emphasis on explicit phonological instruction was associated with substantially reduced variation in class word reading scores over time, and that a relatively weak emphasis on explicit phonological instruction was associated with increased variation of class word reading scores over time, adds to research demonstrating the superiority of explicit phonological instruction over implicit phonological instruction.

It seems likely that the large achievement gap evident between low- and high-achieving readers in New Zealand remains wide because the predominantly whole-language methods persisting in this country fail to provide the kind of intensive phonics instruction that at-risk children need in the first year of school. In order to address this problem, systemic changes need to be made whereby at-risk children are provided with explicit, isolated instruction in phonological awareness and decoding skills. Instruction needs to be systematic, unique to individual children's needs, and sufficiently intensive to eliminate the gaps that exist at school-entry.

If change is to be systemic, however, it needs to be advocated by education leadership (Tunmer et al., 2013). Ministry of Education initiatives need to emphasise that some children come to school with greater literacy-related needs than others, that children with phonological weaknesses need to be identified at school entry (if not before), and that these children must have their learning needs addressed immediately. Teachers of new-entrant children at risk of reading failure may also require further professional development to assist them to better address the literacy learning needs of all children.

\section{REFERENCES}

Allan, J., \& Harwood, V. (2014). Medicus interruptus in the behaviour of children in disadvantaged contexts in Scotland. British Journal of Sociology of Education, 35(3), 413-431.

Anderson, C. (2009). The five pillars of reading. Library Media Connection, 28(2), 22.

Anthony, J. L., \& Francis, D. J. (2005). Development of phonological awareness. Current Directions in Psychological Science, 14(5), 255-259.

Anthony, J. L., Lonigan, C. J., Driscoll, K., Phillips, B. M., \& Burgess, S. R. (2003). Phonological sensitivity: A quasi-parallel progression of word structure units and cognitive operations. Reading Research Quarterly, 38(4), 470-487.

Arrow, A. W., \& Tunmer, W. E. (2012). Contemporary reading acquisition theory: The conceptual basis for differentiated reading instruction. In S. Suggate \& E. Reese (Eds.), Contemporary debates in childhood and education (pp. 241-249). London: Routledge.

Chamberlain, M. (2013). PIRLS 2010/11 in New Zealand: An overview of findings from the third cycle of the Progress in International Reading Literacy Study (PIRLS). Retrieved from http://www.educationcounts.govt.nz/publications/ series/2539/114981/125051

Clay, M.M. (2005). Literacy lessons designed for individuals. Part one: Why? When? How? Portsmouth, $\mathrm{NH}$ : Heinemann.

Clay, M. M., \& Cazden, C. B. (1990). A Vygotskian interpretation of reading recovery. In L. C. Moll (Ed.), Vygotsky and education (pp. 206-222). New York: Cambridge University Press. 
Conners, F. A., Loveall, S. J., Moore, M. S., Hume, L. E., \& Maddox, C. D. (2011). An individual differences analysis of the self-teaching hypothesis. Journal of Experimental Child Psychology, 108(2), 402-410.

Connor, C. M., Morrison, F. J., \& Katch, L. E. (2004). Beyond the reading wars: Exploring the effect of child-instruction interactions on growth in early reading. Scientific Studies of Reading, 8(4), 305336.

Creswell, J. W. (2008). Educational research: Planning, conducting, and evaluating quantitative and qualitative research (3rd Ed.). Upper Saddle River, NJ: Pearson.

D’Angiulli, A., Siegel, L. S., \& Hertzman, C. (2004). Schooling, socioeconomic context and literacy development. Educational Psychology, 24(6), 867883.

Eber, L. (2001). School-based wraparound and its connection to positive behavior interventions and supports: A component of safe/effective schools for all students. Retrieved from http://ezproxy.massey.ac.nz/login?url=http://search. ebscohost.com/login.aspx?direct=true $\& \mathrm{db}=$ eric $\& A$ $\mathrm{N}=\mathrm{ED} 453482 \&$ site=eds-live \&scope=site

Education Review Office (2009). Reading and writing in years 1 and 2, December 2009. Wellington, New Zealand.

Ehri, L. C. (2004). Teaching phonemic awareness and phonics: An explanation of the national reading panel meta-analyses. In P. D. McCardle \& V. Chhabra (Eds.), The voice of evidence in reading research (pp. 153-186). Baltimore, Md: Brookes Publishing.

Ehri, L. C. (2005). Learning to read words: Theory, findings, and issues. Scientific Studies of Reading, 9(2), 167-188.

Gough, P. B., \& Tunmer, W. E. (1986). Decoding, reading, and reading disability. Remedial and Special Education, 7, 6-10.

Greaney, K. (2004). First to fourth to thirteenth and (in all probability), still dropping? New Zealand's international literacy results: Some personal thoughts about the reasons for the gap. DELTA, 56(2), 53-64.

Greaney, K. (2011). The multiple cues or "searchlights" word reading theory: Implications for reading recovery. Perspectives on Language and Literacy, 15-19.
Greaney, K., \& Arrow, A. (2012). Phonological-based assessment and teaching within a first year reading program in New Zealand. Australian Journal of Language and Literacy, 35(1), 9-32.

Hansen, M., Litzelman, A., Marsh, D. T., \& Milspaw, A. (2004). Approaches to serious emotional disturbance: Involving multiple systems. Professional Psychology: Research and Practice, 35(5), 457-465.

Harwood, V. (2006). Diagnosing 'disorderly' children: A critique of behaviour disorder discourses: London; New York : Routledge, 2006.

HM Treasury Department for Education and Skills (2007). Policy review of children and young people. A discussion paper. Norwich, UK: Author.

Jimerson, S. R., Oakland, T. D., \& Farrell, P. (2006). The handbook of international school psychology. Thousand Oaks: Sage Publications, [2006], c2007.

Juel, C., \& Minden-Cupp, C. (2000). Learning to read words: Linguistic units and instructional strategies. Reading Research Quarterly, 35(4), 458-492.

Kieffer, M. J. (2010). Socioeconomic status, English proficiency, and late-emerging reading difficulties. Educational Researcher, 39(6), 484-486.

Kyte, C. S., \& Johnson, C. J. (2006). The role of phonological recoding in orthographic learning. Journal of Experimental Child Psychology, 93(2), 166-185.

Lundberg, I., Larsman, P., \& Strid, A. (2012). Development of phonological awareness during the preschool year: The influence of gender and socio-economic status. Reading and Writing, 25(2), 305-320.

McNamara, J. K., Scissons, M., \& Gutknecth, N. (2011). A longitudinal study of kindergarten children at risk for reading disabilities: The poor really are getting poorer. Journal of Learning Disabilities, 44(5), 421-430.

Ministry of Education (2003). Effective literacy practice in years 1 to 4 . Wellington, New Zealand: Learning Media.

National Early Literacy Panel (2008). Developing early literacy: Report of the national early literacy panel. Jessup, MD.

National Reading Panel (2000). Findings and determinations of the national reading panel by topic areas. Report of the National Reading Panel: Teaching Children to Read, 7-18. 
Noble, K. G., Farah, M. J., \& McCandliss, B. D. (2006). Socioeconomic background modulates cognitionachievement relationships in reading. Cognitive Development, 21(3), 349-368.

Pressley, M. (2006). Reading instruction that works: The case for balanced teaching. New York, NY: Guilford Publications.

Rayner, K., Foorman, B. R., Perfetti, C. A., Pesetsky, D., \& Seidenberg, M. S. (2001). How psychological science informs the teaching of reading. Psychological Science, 2(2), 31-74.

Ryder, J. F., Tunmer, W. E., \& Greaney, K. T. (2008). Explicit instruction in phonemic awareness and phonemically based decoding skills as an intervention strategy for struggling readers in whole language classrooms. Reading and Writing, 21(4), 349-369.

Shankweiler, D., \& Fowler, A. E. (2004). Questions people ask about the role of phonological processes in learning to read. Reading and Writing, 17(5), 483-515.

Share, D.L. (1999). Phonological recoding and selfteaching: Sine qua non of reading acquisition. Cognition, 55(2), 151-218.

Simos, P. G., Fletcher, J. M., Sarkari, S., BillingsleyMarshall, R., Denton, C. A., \& Papanicolaou, A. C. (2007). Intensive instruction affects brain magnetic activity associated with oral word reading in children with persistent reading disabilities. Journal of Learning Disabilities, 40(1), 37-48.

Smith, F., \& Goodman, K. S. (1971). On the psycholinguistic method of teaching reading. The Elementary School Journal, 71(4), 177-181. doi: $10.2307 / 1000548$

Stanovich, K. E. (1986). Matthew effects in reading: Some consequences of individual differences in the acquisition of literacy. Reading Research Quarterly, 21(4), 360-407.

Stuart, M., Stainthorp, R., \& Snowling, M. (2008). Literacy as a complex activity: Deconstructing the simple view of reading. Literacy, 42(2), 59-66.

Torgesen, J. K. (2004). Lessons learned from research on interventions for students who have difficulty learning to read. In P. D. McCardle \& V. Chhabra (Eds.), The voice of evidence in reading research (pp. 355-382). Baltimore, Md: P. H. Brookes.
Torgesen, J. K., Alexander, A. W., Wagner, R. K., Rashotte, C. A., Voeller, K. K. S., \& Conway, T. (2001). Intensive remedial instruction for children with severe reading disabilities: Immediate and long-term outcomes from two instructional approaches. Journal of Learning Disabilities, 34(1), 33-58+78.

Tracey, D. H., \& Morrow, L. M. (2006). Lenses on reading: An introduction to theories and models. New York, NY: Guilford Publications.

Tunmer, W. E., \& Chapman, J. W. (2003). The reading recovery approach to preventive early intervention: As good as it gets? Reading Psychology, 24(3-4), 337-360.

Tunmer, W. E., Chapman, J. W., Greaney, K. T., Prochnow, J. E., \& Arrow, A. W. (2013). [Why the New Zealand national literacy strategy has failed and what can be done about it: Evidence from the Progress in International Reading Literacy Study (PIRLS) 2011.].

Tunmer, W. E., Nicholson, T., Greaney, K. T., Prochnow, J. E., Chapman, J. W., \& Arrow, A. W. (2008). PIRLS before swine: A critique of New Zealand's national literacy strategy. New Zealand Journal of Educational Studies, 43(2), 105-119.

Tunmer, W. E., \& Prochnow, J. E. (2009). Cultural relativism and literacy education. In R. Openshaw \& E. Rata (Eds.), The politics of conformity in New Zealand (pp. 154-190). North Shore, New Zealand: Pearson.

Van Acker, R. (2007). Antisocial, aggressive, and violent behavior in children and adolescents within alternative education settings: Prevention and intervention. Preventing School Failure, 51(2), 5-12.

Xue, Y., \& Meisels, S. J. (2004). Early literacy instruction and learning in kindergarten: Evidence from the early childhood longitudinal study - Kindergarten class of 1998-1999. American Educational Research Journal, 41(1), 191-229. 


\section{AUTHOR PROFILES}

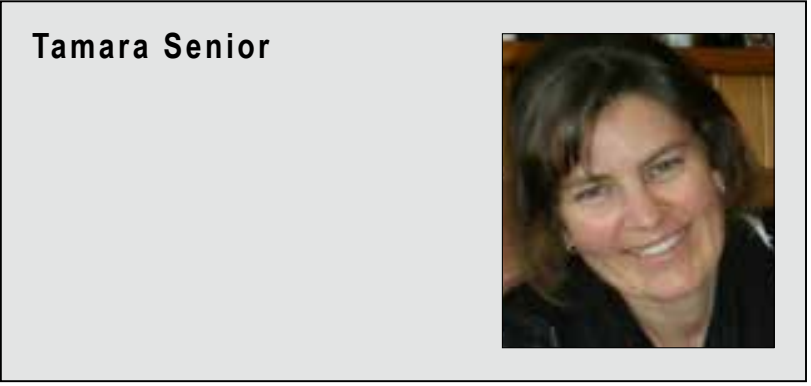

Tamara Senior has a Masters in Educational Psychology from Massey University. She has approximately 10 Years teaching experience, mostly teaching in years 0-2. Tamara recently completed her Educational Psychologist internship through Massey University and is now working as a psychologist in Rotorua.

\section{Email:}

tamsenior77@yahoo.com.au

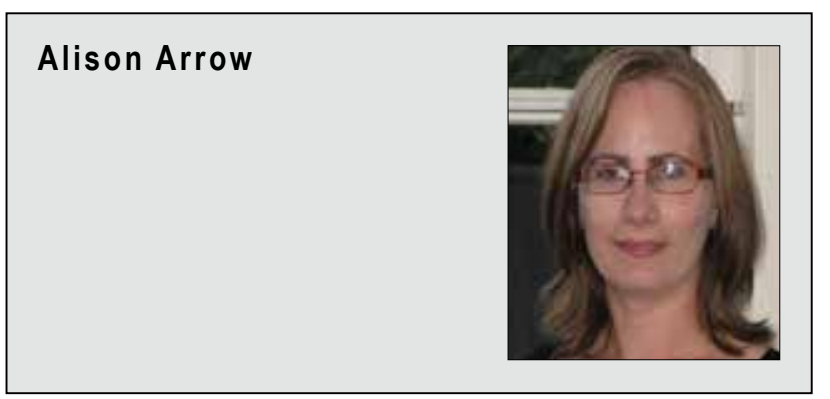

Alison Arrow, PhD, is a senior lecturer in literacy at Massey University. Alison's research interests include the development of emergent literacy, particularly alphabet knowledge and phonological awareness, and what knowledge primary school children use to read and spell. Alison is currently involved in research that examines how children use digital technology for their literacy learning, and in longitudinal research following children learning to read and write.

\section{Email:}

A.W.Arrow@massey.ac.nz

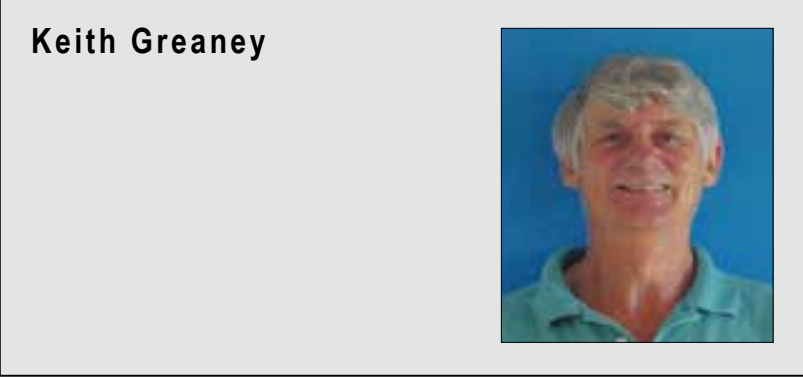

Dr Keith Greaney recently retired from his position as a senior lecturer in the Institute of Education at Massey University. Here he taught both undergraduate and post graduate papers in literacy education and researched and supervised in this area. Keith was a primary school teacher for 28 years including 12 years as an RT:Lit. 